hospitalisation. This real world study aimed to determine the use of COPD patients on long-term azithromycin.

Methods This retrospective review of 42 COPD patients with a minimum of 12 months of follow up for each patient. While previous studies have shown daily use due to side effects and tolerability issues we commenced all patients on $250 \mathrm{mg}$ three times a week. Patients with co-existing asthma, bronchiectasis, with non-tuberculosis bacteria, on nebulised antibiotics were excluded.

Results and Discussion 42 patients (19 males, 23 females), 8 ex-smokers, 24 smokers, 1 non-smoker and 9 unclassified. The mean age of 74 years (59-97) and mean BMI of 31.3. 10 of these patients were immunosuppressed and dose of azithromycin prescribed to patients was $250 \mathrm{mg}$ three times a week (97\%) and 500mg three times a week (4\%). 47.6\% (20) had to discontinue azithromycin use to various reasons.

The average infections in the pre-treatment group was 7 $( \pm 2.77)$ versus $2( \pm 1.94)$ in the subsequent 12 months with a statistically significance $(p<0.05)$, and a decrease in difference was seen in the number of hospitalisations. 14 (33\%) patients saw a $100 \%$ reduction in the infection rate following azithromycin use. As this was a retrospective study, the number of infections depended on reporting from the patient and may be influenced by recall bias.

Conclusion The number of infective exacerbations was significantly decreased with the introduction of azithromycin therapy. It is important that an ECG to measure QT changes before and after commencing therapy to monitor the harmful effects of the macrolide. Hearing loss is the major side effect faced by patients, and this must be stressed to patients as it happens more frequently than originally thought. The dosage of $250 \mathrm{mg}$ three times a week seems to be work as well as daily azithromycin as suggested in the subsequent BTS guideline 2020 .

\section{P83 CHRONIC OBSTRUCTIVE PULMONARY DISEASE - OBSTRUCTIVE SLEEP APNOEA OVERLAP SYNDROME MANAGEMENT - A NATIONAL SURVEY}

TB Fretwell, K George, SD West. Newcastle upon Tyne Hospitals Foundation Trust, Newcastle, UK

\subsection{6/thorax-2021-BTSabstracts. 193}

Introduction When chronic obstructive pulmonary disease (COPD) and obstructive sleep apnoea syndrome (OSA) occur together it is known as the COPD-OSA Overlap Syndrome. Studies show a prevalence of $1-4 \%$ but as high as $66 \%$ in people with moderate-severe COPD. As it is not routine practice to screen COPD patients for OSA, it is likely underdiagnosed. Expert opinion suggests those with severe hypercapnia should be considered for non-invasive ventilation (NIV) and those without for continuous positive airway pressure (CPAP). This is based upon existing randomised controlled trials (RCT) in COPD and obesity hypoventilation. There are no RCTs to determine the clinical efficacy of CPAP in comparison to NIV in COPD-OSA. The aim of this study was to gauge current national practice via an electronic survey.

Methods An electronic survey was sent via national email networks to assess respondents management of COPD-OSA. This contained case vignettes with varying severities of OSA, COPD, hypercapnia and the presence or absence of a history of acute hypercapnic respiratory failure (AHRF).
Results There were 88 survey respondents, from 40 institutions. $74 \%$ were Doctors, $11 \%$ Nurse Specialists/Consultants, $3 \%$ Physiotherapists and 3\% Clinical Scientists. Only 8\% reported their COPD service routinely screened all patients for OSA. In the clinical vignettes with a $\mathrm{PaCO} 2$ below $<7 \mathrm{kPa}$, most respondents selected CPAP as first line therapy: Case $1=91 \%(\mathrm{PaCO} 2$ 6.2), Case $3=80 \%(\mathrm{PaCO} 2$ 6.7). Case 4 had a history of AHRF and $84 \%$ selected NIV as first line treatment. In cases 2 and 5 the $\mathrm{PaCO} 2$ was $>7 \mathrm{kPa}$ and there was no history of AHRF. In these cases, there was clinical equipoise. In case 2: 69\% selected NIV and 26\% CPAP. In case 5: 48\% selected CPAP and 52\% NIV.

Conclusions Our study shows that in patients with COPDOSA with a PaCO2 below $7 \mathrm{kPa}$, most respondents would treat with CPAP first line. However, in those patients with no history of AHRF who have a $\mathrm{PaCO} 2>7 \mathrm{kPa}$, there was clinical equipoise amongst NHS specialists with regards to first line therapy. There are currently no RCTs in this area and further research is required.

\section{P84 IDENTIFYING CHRONIC OBSTRUCTIVE PULMONARY DISEASE - OBSTRUCTIVE SLEEP APNOEA OVERLAP SYNDROME - DOES IT MATTER?}

TB Fretwell, RE Sobala, D McCourt, IB Bittiner, A Armstrong, B Messer, SD West. Newcastle upon Tyne Hospitals Foundation Trust, Newcastle, UK

\subsection{6/thorax-2021-BTSabstracts. 194}

Introduction The prevalence of Chronic Obstructive Pulmonary Disease - Obstructive Sleep Apnoea Overlap Syndrome (COPD-OSA) is $1-4 \%$ in the general population but is higher in those with severe airways obstruction. It has a higher rate of hospitalisation, exacerbation frequency and mortality than in either condition alone, yet there are no randomised control trials (RCT) to guide management. Our aim was to assess the prevalence of obesity and OSA within a COPD home ventilation cohort as we hypothesise that COPD-OSA is under recognised.

Methods A retrospective analysis was performed of active patients in a regional Home Ventilation Service. 221 patients were identified who were initiated on non-invasive ventilation (NIV) between 2009-2021 and whose documented cause of respiratory failure was COPD. Using electronic healthcare records, we collected the body mass index (BMI), diagnosis of OSA, PaCO2 at time of referral and route of referral.

Results 217 patients had a BMI recorded; in 50\% it was $\geq 30$ and $24 \% \geq 40.28 \%$ had diagnosed OSA but in those with a BMI of $\geq 30,49 \%$ had OSA (table 1). $53 \%$ of those with OSA had a previous trial of continuous positive airway pressure (CPAP). $58 \%$ of referrals were made as outpatients. None had a documented formal diagnosis of 'COPD-OSA Overlap Syndrome'.

\begin{tabular}{lllllll}
\multicolumn{2}{l}{ Abstract P84 Table 1} & \multicolumn{5}{l}{ Prevalence of OSA within BMI ranges } \\
\hline BMI & $<18.5$ & $18.5-$ & $25-$ & $30-$ & $35-$ & $\geq 40$ \\
& $(n=24)$ & 24.9 & 29.9 & 34.9 & 39.9 & $(n=51)$ \\
& & $(n=44)$ & $(n=40)$ & $(n=33)$ & $(n=25)$ & \\
\hline $\begin{array}{l}\text { OSA } \\
\text { Prevalence }\end{array}$ & $4.2 \%$ & $2.3 \%$ & $12.5 \%$ & $33.3 \%$ & $48.0 \%$ & $58 \%$ \\
\hline
\end{tabular}


Conclusion 50\% of COPD patients requiring home ventilation were obese and $28 \%$ had diagnosed OSA. Although this study was a retrospective electronic record review, it suggests COPD-OSA Overlap Syndrome is common and underrecognised. OSA and COPD alone have RCT evidence supporting CPAP and NIV therapy; there is none in COPD-OSA. Given the high prevalence and mortality, it needs greater recognition as a discrete disease entity and urgent RCTs to establish optimum therapy, CPAP or NIV. Currently there is national variation in treatment based upon expert opinion and clinical availability. Yet there are significant cost differences and possibly different treatment efficacies. The majority of patients had NIV initiated in the outpatient setting, suggesting there would be time to arrange sleep studies to establish the COPD-OSA diagnosis prior to CPAP or NIV initiation. Given the high prevalence, should we be screening this high-risk cohort?

\section{P85 RESPIRATORY DEPRESSION IN OPIOID DEPENDENT CHRONIC OBSTRUCTIVE PULMONARY DISEASE PATIENTS}

${ }^{1} \mathrm{~B}$ Tas, ${ }^{1,4} \mathrm{NJ}$ Kalk, ${ }^{2,5} \mathrm{PSP}$ Cho, ${ }^{3} \mathrm{M}$ Lozano-Garcia, ${ }^{2} \mathrm{GF}$ Rafferty, ${ }^{4} \mathrm{M}$ Kelleher, ${ }^{2} \mathrm{~J}$ Moxham, ${ }^{1,4} \mathrm{~J}$ Strang, ${ }^{5,6} \mathrm{CJ}$ Jolley. ${ }^{1}$ National Addiction Centre, Institute of Psychiatry, Psychology and Neuroscience (IoPPN) at King's College London, London, UK; ${ }^{2}$ Division of Asthma, Allergy and Lung Biology, King's College London, London, UK; ${ }^{3}$ Biomedical Signal Processing and Interpretation group, Institute for Bioengineering of Catalonia (IBEC), Catalonia, Spain \& Biomedical Research Networking Centre in Bioengineering, Biomaterials and Nanomedicine (CIBERBBN), Barcelona, Spain; ${ }^{4}$ South London and Maudsley NHS Foundation Trust, London, UK; ${ }^{5}$ Centre of Human and Aerospace Physiological Sciences, King's College London, London, UK; ${ }^{6}$ King's College Hospital NHS Foundation Trust, King's Health Partners, London, UK

\subsection{6/thorax-2021-BTSabstracts.195}

Introduction In the UK, opioid-related deaths are at record numbers after continually increasing year-on-year (ONS, 2019). This increase is believed to be driven by an ageing cohort of people with Opioid Use Disorder (OUD) and a high prevalence of comorbidities including chronic obstructive pulmonary disease (COPD). Our previous findings suggest that the degree of acute opioid-induced respiratory depression is greatest in OUD patients with chronically-suppressed neural respiratory drive (NRD) as a consequence of drug misuse (Jolley et al.,2015). We investigated the severity of respiratory depression in OUD and tested whether OUD exhibit more severe respiratory depression than matched controls.

Methods A convenience sample of opioid addicts receiving treatment at a community Drug \& Alcohol Treatment Centre were recruited: OUD with normal lung function (OUD) and OUD with comorbid COPD (OUD-LD). OUD groups were matched with healthy controls (HC) and COPD patients with no history of drug/alcohol addiction (LD-Controls) from our laboratory database.

$\mathrm{SpO}_{2} \%$, end-tidal $\mathrm{CO}_{2} \quad\left(\mathrm{ETCO}_{2}\right)$, transcutaneous $\mathrm{CO}_{2}$ $\left(\mathrm{TcCO}_{2}\right)$, respiratory airflow and NRD index (NRDI), quantified using second intercostal space parasternal muscle electromyography (EMG $\left.\mathrm{G}_{\text {para }}\right)$, were measured continuously over 40 mins at rest. Significant respiratory depression was defined as: $\mathrm{SpO}_{2} \%<90 \%$ for $>10 \mathrm{~s}, \mathrm{ETCO}_{2}$ per breath $>6.5 \mathrm{kPa}$, $\mathrm{TcCO}_{2}$ overall mean $>6.5 \mathrm{kPa}$, respiratory pauses (absence of inspiratory airflow) $>10$ s.

Results Seven OUD patients (5M/2F, age: 48(46-52), $\mathrm{FEV}_{1} \%$ pred(\%): 96.1(90.5-96.5), FEV\%FVC(\%): 74.7(71.9-76.8)), 13 OUD-LD $\left(11 \mathrm{M} / 2 \mathrm{~F}\right.$, age: 49(42-55), $\mathrm{FEV}_{1} \%$ pred(\%): 77.1 (66.8-90.1), FEV\%FVC(\%): 60.2(48.7-64.3)), $7 \mathrm{HC}(6 \mathrm{M} / 1 \mathrm{~F}$, age: 50(45-57), FEV $_{1} \%$ pred(\%): 100(97.5-110.3), FEV\%FVC

\begin{tabular}{|c|c|c|c|c|c|c|c|c|c|}
\hline Number & $\begin{array}{l}\mathrm{SpO}_{2}<90 \% \\
>10 \mathrm{~s}\end{array}$ & $\begin{array}{l}\mathrm{ETCO}_{2} \text { breaths } \\
>6.6 \mathrm{kPa}\end{array}$ & $\begin{array}{l}\mathrm{TcCO}_{2}>6 \mathrm{kPa} \\
\text { mean }\end{array}$ & $\begin{array}{l}\text { Resp Pauses } \\
>10 \mathrm{~s}\end{array}$ & Number & $\begin{array}{l}\mathrm{SpO}_{2}<90 \% \\
>10 \mathrm{~s}\end{array}$ & $\begin{array}{l}\mathrm{ETCO}_{2} \text { breaths } \\
>6.6 \mathrm{kPa}\end{array}$ & $\begin{array}{l}\mathrm{TcCO}_{2}>6 \mathrm{kPa} \\
\text { mean }\end{array}$ & $\begin{array}{l}\text { Resp Pauses } \\
>10 \mathrm{~s}\end{array}$ \\
\hline \multicolumn{5}{|c|}{ OUD without LD: } & \multicolumn{5}{|c|}{ Healthy controls: } \\
\hline 1 & & $\checkmark$ & & $\checkmark$ & 1 & & $\checkmark$ & & \\
\hline $2^{1}$ & & $\checkmark$ & $\checkmark$ & $\checkmark$ & 2 & & $\checkmark$ & & \\
\hline 5 & $\checkmark$ & & & $\checkmark$ & 3 & & & & \\
\hline 8 & & & $\checkmark$ & $\checkmark$ & 4 & & & & \\
\hline 9 & & $\checkmark$ & $\checkmark$ & & 5 & & & & \\
\hline 16 & & $\checkmark$ & & & 6 & & & & \\
\hline $18^{1}$ & & $\checkmark$ & & $\checkmark$ & 7 & & & & \\
\hline \multicolumn{5}{|l|}{ OUD-LD: } & \multicolumn{5}{|c|}{ LD-controls: } \\
\hline $3^{1}$ & & & $\checkmark$ & & 1 & & & & \\
\hline $4^{1}$ & & $\checkmark$ & & & 2 & & & & \\
\hline $6^{1}$ & $\checkmark$ & $\checkmark$ & & $\checkmark$ & 3 & & & & \\
\hline $7^{1}$ & & & $\checkmark$ & & 4 & & & & \\
\hline $10^{1}$ & $\checkmark$ & & $\checkmark$ & & 5 & & & & \\
\hline 11 & $\checkmark$ & $\checkmark$ & & $\checkmark$ & 6 & & & & \\
\hline 12 & & $\checkmark$ & & & 7 & & & & \\
\hline 13 & & $\checkmark$ & & & 8 & & & & \\
\hline 14 & $\checkmark$ & $\checkmark$ & $\checkmark$ & $\checkmark$ & 9 & & $\checkmark$ & & \\
\hline $15^{1}$ & & & & $\checkmark$ & 10 & & $\checkmark$ & & \\
\hline 17 & & $\checkmark$ & $\checkmark$ & $\checkmark$ & 11 & & & & \\
\hline 19 & & $\checkmark$ & & $\checkmark$ & 12 & & & & \\
\hline 20 & & $\checkmark$ & & & 13 & & & & \\
\hline
\end{tabular}

